\title{
A Case Study in the Evolution of Digital Services for Science and Engineering Libraries
}

\author{
CAROL HUNTER, SHERRY LAKE, CARLA LEE, \\ and ANDREW SALLANS \\ University of Virginia, Charlottesville, VA, USA
}

\begin{abstract}
Building on experiences from earlier digital initiatives and partnerships, the University of Virginia has developed new services and forged new collaborations between traditional information technology and library units in support of changing approaches to science and engineering research and education. Over the past 4 years, the library has evolved through numerous service models, changes in institutional vision, and budgetary shortfalls and has emerged with a new understanding of where to invest resources and energy for coming challenges.
\end{abstract}

KEYWORDS collaboration, information technology, library organization, library services, library space, reorganization, science and engineering libraries, service models, strategic planning, user services

\section{BACKGROUND}

The Research Computing Lab (RCL) at the Charles L. Brown Science and Engineering Library of the University of Virginia provides research and instructional support for advanced technology and methodology in the science and engineering disciplines. This nontraditional library services unit was created in response to changing methods in science and engineering research and instruction. To meet these changing needs, the RCL aims to provide seamless information services, ranging from the identification and acquisition of information and data to the complex analysis and modeling of these sets. The staff brings a traditional full-services library public services approach, paired 
with the technical depth that is critical to success in today's science and engineering environment. In the first three years, day-to-day support has grown tremendously and with increasing complexity. Additionally, the staff has become increasingly involved in longer term consultation and training with students, faculty, and researchers. These consultations range from serving as technical experts for a class of students working on complex data projects, to multiyear consultations with faculty and departments who are aiming to preserve, use, and improve decades of data (both analog and digital). The multifaceted nature of science and engineering research and instruction today demands these new capabilities among librarians. The RCL complements the suite of information services offered by the Library and works in close partnership with subject librarians to provide seamless support across the entire research lifecycle.

\section{LITERATURE REVIEW}

The RCL model is built upon a merging of library and information technology (IT) services and staff. A search through the literature shows many examples of libraries and IT services collaborating on physical spaces. Some of these examples have been mergers of entire library and IT departments. Libraries and information technology (IT) services have worked closely with each other since libraries became automated. This relationship in recent years has increased and the bond between them has become very close. Their shared commitment to the effective management of information and the library's increased dependence on digital resources has brought them together (McKinzie, 2007). In 2007, the journal Reference Services Review ${ }^{1}$ published a special issue on library and IT mergers that included survey results on the successfulness of information services, a case study on the experience of such a merger and an article devoted to collaboration planning. Hernon and Powell (2008) compiled examples of different types of information services collaborations such as tutoring and writing centers, information and learning commons, information arcades, and facilities for multimedia production and delivery. Most mergers have taken place at liberal arts colleges, where both library and IT units were smaller. These mergers were actual organizational mergers, where two units were fully joined into one, rather than collaborative agreements with shared space and resources (Foster, 2008). Only recently has the literature shown collaborative services where librarians and IT professionals work closely with researchers and their research projects (Garritano \& Carlson, 2009; Luce, 2008; Gold, 2007).

According to the EDUCAUSE: Core Data Survey-2007, 13.7\% of the 994 reporting institutions had libraries reporting to the top IT administrator. Of these library-IT merged institutions, $15.9 \%$ were Master's Colleges \& Universities and 17.8\% were smaller liberal arts (Baccalaureate Colleges, 2007). 
Only 7.8\% of the institutions were Doctoral/Research Universities (Hawkins \& Rudy, 2008). Comparing this to the 2005 survey, the number of doctoral and research universities that have merged library-IT services has stayed about the same over the 2-year period (Hawkins \& Rudy, 2006). ${ }^{2}$ According to Foster (2008), the model of library and IT mergers does not work at large research universities. In many large research universities, libraries and IT departments are not unified, and sometimes not even collaborating. Patrons often go to each group independently for access to resources and services.

The 2006 National Science Foundation report on Science and Engineering Indicators indicated that collaboration in science research was becoming more commonplace (National Science Board, 2006). This shift in science research, e-Science, led academic libraries to assess the way they provide services and to seek new opportunities to collect and organize scientific information, in support of the new e-Science agenda. In a previous report the National Science Board (2005) outlined roles that librarians could play in data management and the data deluge of distributed global collaborations. A report from the Association of Research Libraries (2006) examined the role of research and academic libraries with other partners in the stewardship of scientific and engineering digital data.

With the emergence of e-Science and data curation issues in research libraries, the Association of Research Libraries (ARL) created a joint task force to recommend and initiate response strategies for ARL libraries. In its report, the Joint Task Force on Library Support for E-Science (2007, p. 17) suggested that research libraries could partner in the development of e-Science by being an "active participant[s] in the development of research infrastructure, including systems and services to support the processes of research and the full life cycle of research assets." 3 It further stated that to accomplish this, libraries will need "knowledgeable and skilled research library professionals with capacity to contribute to e-Science and to shape new roles and models of service." ${ }^{4}$ Even before this Task Force presented its report, Purdue University Libraries had created a unique library model where librarians and faculty in engineering, science, and technology served as faculty collaborators on sponsored research projects (Brandt, 2007).

To successfully contribute to e-Science, future librarians and data scientists will need to be trained (Garritano \& Carlson, 2009). To overcome the shortages of qualified professionals to manage the increasing amounts of data in the sciences, the Graduate School of Library and Information Science at the University of Illinois at Urbana-Champaign (UIUC), developed two educational programs: a Biological Information Specialist masters degree and a concentration in Data Curation (Palmer et al., 2007). In response to requests from practicing librarians, UIUC held its first Summer Institute on Data Curation in June 2008. The goal of this workshop was to address the growing need for data services and curation activities in academic and research libraries. 
Since the e-Science Task Force report in 2007, "E-Science and Libraries" has been an important theme for several conferences and forums. One example was the May 2008 CIC's Center for Library Initiatives conference, entitled "Librarians \& e-Science: Focusing Towards 20/20." This conference included scientists and librarians discussing collaborations and the librarians' roles in e-Science (Committee on Institutional Cooperation, 2008). The ARL-CNI ${ }^{5}$ Fall Forum, entitled Re-inventing Science Librarianship: Models for the Future, was aimed to broaden the understanding of trends in e-Science research and support leadership in applying these trends in the development of new library roles. To support these goals, the forum featured speakers on e-Science trends, data curation issues, virtual organizations and library education support for new roles (Association of Research Libraries, 2008). In 2009, the ACRL Science and Technology Section of the ALA Annual Conference sponsored a poster session entitled Big Science, Little Science, E-Science: The Science Librarian's Role in the Conversation. This session was specifically designed to explore the science librarian's role concerning data and data curation in scientific research (Association of College \& Research Libraries: Science \& Technology Section, 2009).

\section{INCEPTION}

In 2005, a pilot program was launched to create a shared collaborative model of service combining reference and information services provided by the Brown Science and Engineering Library with information technology services found within the University's Department of Information Technology and Communication (ITC). The ITC/Library Shared Services Committee had observed that (1) library patrons, particularly students, do not necessarily distinguish which questions should be directed to the library (informational) and which should be handled by ITC (technological); (2) students, faculty, and staff express the need for library spaces to be flexible multitasking environments; and (3) technological needs are inexorably linked to interdisciplinary curricular needs and scholarly research. Together, the ITC/Library Shared Services Committee defined the shared universe of knowledge between the two organizations and developed a common understanding of the distinction between general and specialized support services. The physical location of the ITC help desk consultant was relocated to the central reference and information desk of the library. In addition to serving students and faculty more efficiently and effectively, the shared collaborative model enabled personal relationships and an informal communication network to develop that had never existed between the library and ITC. Joint crosstraining was developed that gave both units insight into their individual functions and the areas that frequently overlap. This is not to say that there were not some challenging aspects. The expectation of student and staff employees 
varied within the library and ITC and the structure and culture of the two organizations were also quite different. The pilot program, however, proved to be successful and its implementation was expanded to other university libraries. The lesson learned was that not one person, unit, or event assures the success of an initiative, but the collaboration and commitment of the whole. A combination of factors-training, oversight, ITC/Library flexibility, continuous communication-assured its success.

In 2006, the library/ITC partnership expanded as ITC's Research Computing Support Group relocated to two libraries to join with library staff in creating two magnet centers, the Scholar's Lab (humanities and social sciences) and the Research Computing Lab (science and engineering) to leverage the expertise of both ITC and the Library to better serve the needs of researchers and scholars and bring them into new collaborative relationships with each other. The library and ITC merged staff, physical resources, and operational budgets to ensure a productive partnership. On the heels of this expanded partnership came the strategic vision for academic infrastructure and high performance computing at the university through the Commission on the Future of the University. The introduction to the November 2007 report of the Commission on the Future of the University's Subcommittee on the Academic Infrastructure at the University of Virginia begins:

\begin{abstract}
At the conclusion of the first quarter of the 21st century, all research and scholarship will be disseminated in digital form and leading universities will provide students and faculty with extensive information and communication infrastructure, abundant access to resources and knowledge navigation systems, and policies that support interdisciplinary collaborations and encourage development of new expertise and non-traditional combinations of skills.
\end{abstract}

This is proving to be a pivotal time to be an academic librarian in the science and engineering arena as the changing nature of scholarship and research demands new approaches to the acquisition, access, manipulation, delivery, and preservation of information and data. The service models that undergird and support this new day are ever unfolding.

\title{
CHANGING MODELS OF SERVICE
}

Over the three years that the Research Computing Lab has been in operation, it has undergone constant change. This change frequently referred to as "transition" is perhaps a misnomer, as a transition implies a defined starting and ending point. A more accurate way of describing the changes taking place might be to consider it an evolution. To understand the management strategy and decisions within the Research Computing Lab, it is important to 
first look at the environmental conditions. The three primary factors that we will analyze will be the arrival of a new university chief information officer (CIO), the release of a new university strategic plan, and a challenging budgetary landscape.

Digital initiatives at the University of Virginia Library started in the late 1990s, initially with units like the Robertson Media Center, Digital Media Lab, Electronic Text (E-Text) Center, Geospatial and Statistical Data center, and the Science \& Engineering Library's Digital initiative (SEDI). In 1997, the Science and Engineering Library created the SEDI lab to support the creation, development, access, and presentation of digital resources for the sciences and engineering disciplines. It was intended to complement the digitization services of the University's E-Text Center, located in the main graduate humanities-focused Alderman Library. The SEDI lab first offered scanning services similar to that of the E-Text Center, then expanded to support multimedia, Web authoring, and statistical and geographic information system software. The SEDI lab ideally provided a space where faculty, staff and students could work on cooperative digital technology projects. To support this objective, students were hired to support the workstations and software in the lab.

On July 1, 2006, the University of Virginia welcomed a new vice president and CIO for the university. These arrivals took place almost simultaneously with the opening of the new interdepartmental, collaborative RCL and Scholars' Lab. This major new university development, the arrival of a new CIO, put the university in a position for substantial change and development. The new CIO brought with him a strong and equally experienced leader, in the position of associate vice president and deputy CIO. Both new additions offered the university many years of working in IT management in a large university setting, having dealt with the challenges of state budgets, academic organizations, and perhaps most important, the creation of a culture that is better-suited to sustain constant change. To accomplish this change, the CIO initiated a new program of transformational "communities," offering staff the opportunity to own their future at the university. "Communities" self-organized around themes to lead the organization to improvement of various institutional problems like security, collaboration, and access. The first year included some major overhauls, such as new e-mail systems, outsourcing initiatives, and staff reorganizations. This effort to invigorate the organization provided a foundation for change around the RCL as well.

During this period of significant change in how IT worked at the university, the RCL was still finding its footing. With its beginning as a collaborative unit, each group contributed something to the collective. At the start, the library offered a strong connection to students and faculty, through a longstanding tradition as a service provider. IT offered experience and a range of technical services new to the libraries through its past life as the Research Computing Support Center. Collectively, the new unit set up a service point, 
established available hours, promoted services and capabilities, and started to market our services to our target constituents.

Several months later, in the spring of 2007, the university was beginning to enact the findings of university strategic plan, the "Commission on the Future of the University." Part of this plan entailed the creation of a facultydriven center for computational science and high performance computing. As those activities had previously been located within the Research Computing Support Center, and had since shifted to the RCL, our plan of operations now needed to be rethought. The RCL management now needed to consider which activities were appropriate to stay and which should become part of the University of Virginia Alliance for Computational Science and Engineering (UVACSE).

Over the ensuing months, the principals of the computational science and high performance computing center began to shape the mission and possible operation plans began to emerge. During this period, the RCL continued to operate with a growth strategy, maintaining consistent availability, and continuing to promote the established service areas and capabilities. Knowing the typical trajectory of a center within the university, we expected it to be quite some time before an actual unit was established to carry out the mission of the computational science and high performance computing initiative. As a first step in developing the center, the two former Research Computing Support Center staff members were allocated to 50\% time on center-related initiatives. We were able to secure funding support to backfill this time, and hired a temporary worker for the year. During this period, the RCL also cosponsored several high-performance computing (HPC) boot camps as a means of fostering future collaborations with UVACSE.

One of our main goals at this point was to establish some key consultation service areas that we could grow and maintain in the future, regardless of external environmental factors. We recognized that specific software support, although important to many of our constituents, can be very risky given the significant dependencies on decisions outside of our control (i.e., university site-licensing, software virtualization, etc.). To accommodate this, we chose to develop a strategy built around consultation and methodologies. We would aim to provide guidance, make recommendations, and consult with patrons about how to do a given task, rather than being in the business of doing a task for them. We chose to promote the service areas of software support, current awareness, data, collaboration, and research communication. Collectively, we view these as being supportive pieces to the entire research lifecycle, rather than just a single point.

A second major component of our new vision and plan came with the prioritization of support. Previously, support areas were strictly parceled out to different people. One person might support statistics, another person might support visualization, and a third might support data. Although we recognize that everyone has individual strengths and experience, we saw 
the need to alter how we provide support due to the need for availability. The previous model proved particularly problematic when someone would go on vacation or be out sick, leaving their area of expertise entirely unsupported. To offer high-availability support services, with limited staff of the required level of expertise, we needed to develop higher-level competencies across the board and restructure how services were delivered. This model also addressed one of the basic cultural differences between the library and IT staff. While the library environment brings with it an expectation of service on demand, especially at a desk, the ITC personnel had a more project-based focus, regarding on-demand interactions as interruptions to work, rather than the work itself. Library staff members are traditionally at the other extreme-having trouble finding time to complete projects, as they are frequently changing gears to help the user at the desk. Ultimately a blending of these two cultures was achieved. We chose to have two staff members focus on what we termed "on-demand" support; essentially walk-up, call-in, or other pressing requests. The other two staff members would focus on "by-appointment" support; primarily working on more in-depth issues with less time sensitivity. Both teams would shift toward the other priority as needed throughout the higher-volume periods of the semester. This prioritization plan would ideally allow us to meet patrons' needs in a timely manner and for us to offer the full range of services at all times.

\section{BRIDGING AND CONNECTING COMMUNITIES}

As we developed the new services in the RCL, it became clear that this unit was establishing a new culture. In fact, it has in many ways become a defining feature of the RCL. Over the years we have been challenged to convince colleagues, both researchers and fellow staff members, as well as our patrons, that the Library was the right place to provide these services. We have made decisions along the way that have allowed us to gain access to new groups and develop skills in entirely unexpected areas. While other university libraries have undergone similar cultural shifts during the same period, we see our approach as being unique in the choice to engage with our constituents in technical areas beyond data curation.

The collaboration between these two units brought some surprising blending of culture, procedures, and policies. As we worked together to establish the operation of the RCL, many of these were administrative. As we worked to develop a shared budget we discovered that the two units had different budget deadlines, which made it difficult to create a coordinated budget and then even more surprising, we found that we budgeted for and tracked items in significantly different ways. For example, as we tried to develop a budget which itemized what each unit was contributing to the collaboration for administrative purposes, we discovered that ITC budgets 
phone and internet centrally, where the library distributes the charge departmentally and did not itemize computer purchases by department, while the library funded the computer both centrally and departmentally depending on function. These difference methods of accounting for resources led to some very complicated bookkeeping, but this also meant that we could draw on strengths from each of the units.

Another area where boundary crossing was a defining characteristic was the location of the lab. The RCL is in a much more visible location than either the small computing lab that preceded it or the Research Computing Support Center, which was located in a less publicly inviting space among offices near the Economics Department. The new space was much larger, and in a recently renovated library, where 3,000-3,500 people were entering each day. Resource centers developed in the past had often located in a specific department, where, even if intended to be multidisciplinary, the department was seen to "own" it, and use rarely went far beyond the faculty and students of the department. The library, on the other hand, is neutral, interdisciplinary space, and sees researchers from a wide range of subject areas among its clientele. While this has meant a great increase in traffic for undergraduate and graduate students, faculty members are less likely to be drop-in users of a public computing space. Most contacts with faculty members continue to be through phone and e-mail, on an appointment basis.

The evolutionary style of development also allowed the library culture some time to adjust its methods to accommodate science and technology research projects. Our early digital projects were parallel to projects that had been successful in the humanities and the arts-production of digital images. Since there were existing workflows and project templates for these types of projects our early work focused on using the existing apparatus applied to new subject matter, such as creating digital photos of herbarium specimens. While this was a fine entrée to the field, it limited our clientele to largely those with large image collections that they wanted to share. As time progressed, our project and our skills became more focused on data services and we have seen our clientele broaden (Figure 1).

One of the critical challenges in developing a new service unit is marketing and outreach. Much like the work of the unit itself, our outreach efforts have required us to think beyond the traditional library methods. In our first year, we developed a speaker series in partnership with our humanities and social sciences focused counterpart, the Scholar's Lab. By bringing in speakers on such topics as large-scale data management, visualization, and building a computational science program, we hoped to provide opportunities for multidisciplinary discourse. While attendance at the talks was good, it did prove more difficult to mix the humanists and technologists than we had hoped, since the groups self-selected back along disciplinary lines. However, the talks did have a positive effect upon our decision to establish our services in direct complement of the research lifecycle. 


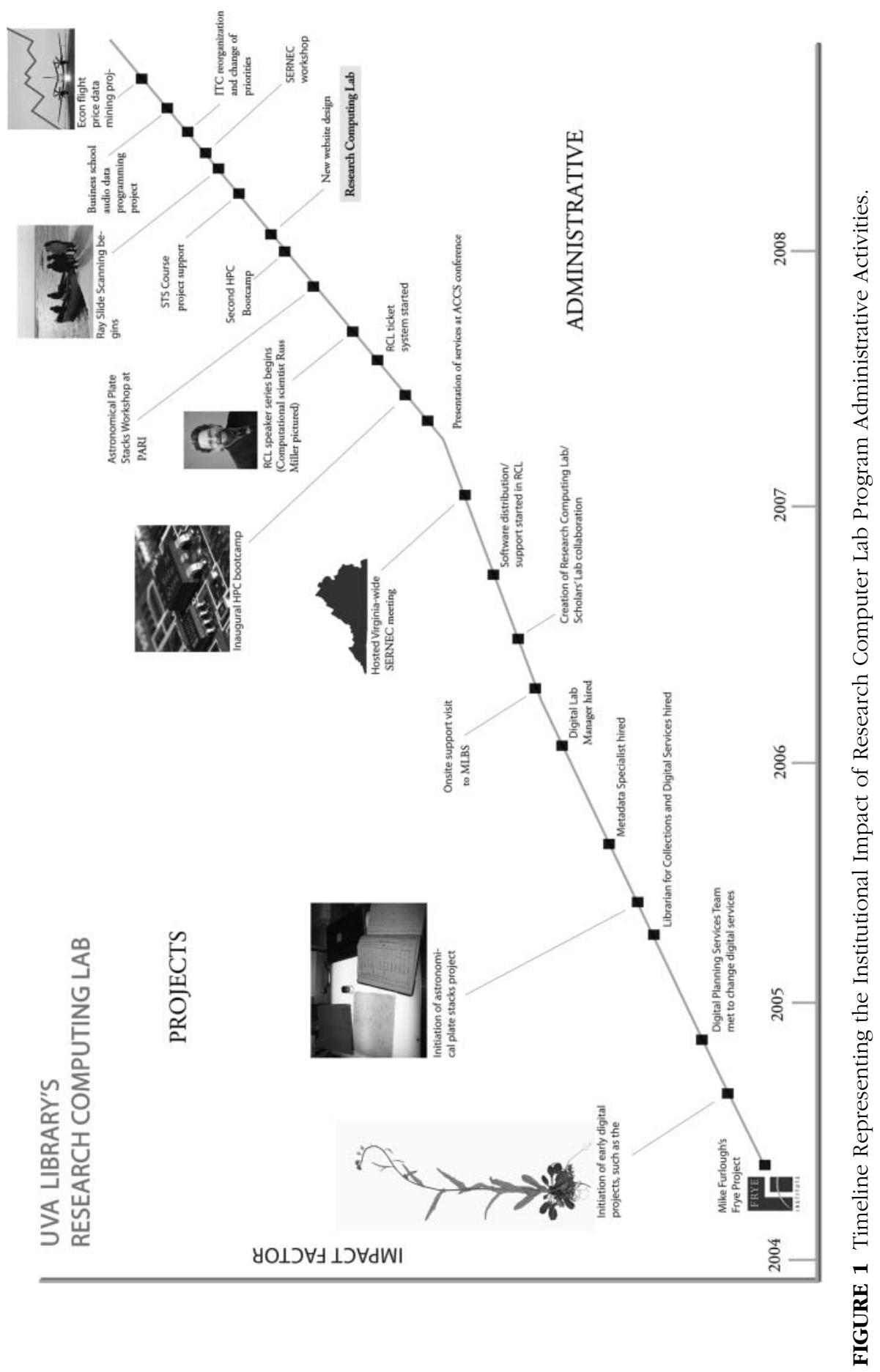


Another outreach effort was intended to blur the boundaries between traditional and e-Science librarianship. With "Research 2.0," we intended to provide a resource fair type of atmosphere, including vendor classes and consultants from across the range of the research cycle, covering topics such as how to develop a book proposal offered by a representative from Wiley, programming classes in MatLab, consultations on how to manage literature citations in RefWorks, and instrumentation demonstrations in LabVIEW. While we provided some opportunity for group discussion of issues and vendor interactions, we found the highest interest in classes on the more advanced use of research software and in research consultations. This event is one example of how we work to integrate the subject expertise and departmental relationships of the traditional subject librarians with the enhanced technical expertise of the RCL staff to provide a full spectrum of services (Figure 2).

Traditional IT Services

- Hardware/Infrastructure Support

- Computer Use Help

- Storage Solutions

- Software Support

- Training on Software/Hardware Use
Traditional Library Services

Journal Review •

Finding \& Retreiving Information

Collection Building •

Library Instruction Classes •

Subject Expertise •

Departmental Contacts •

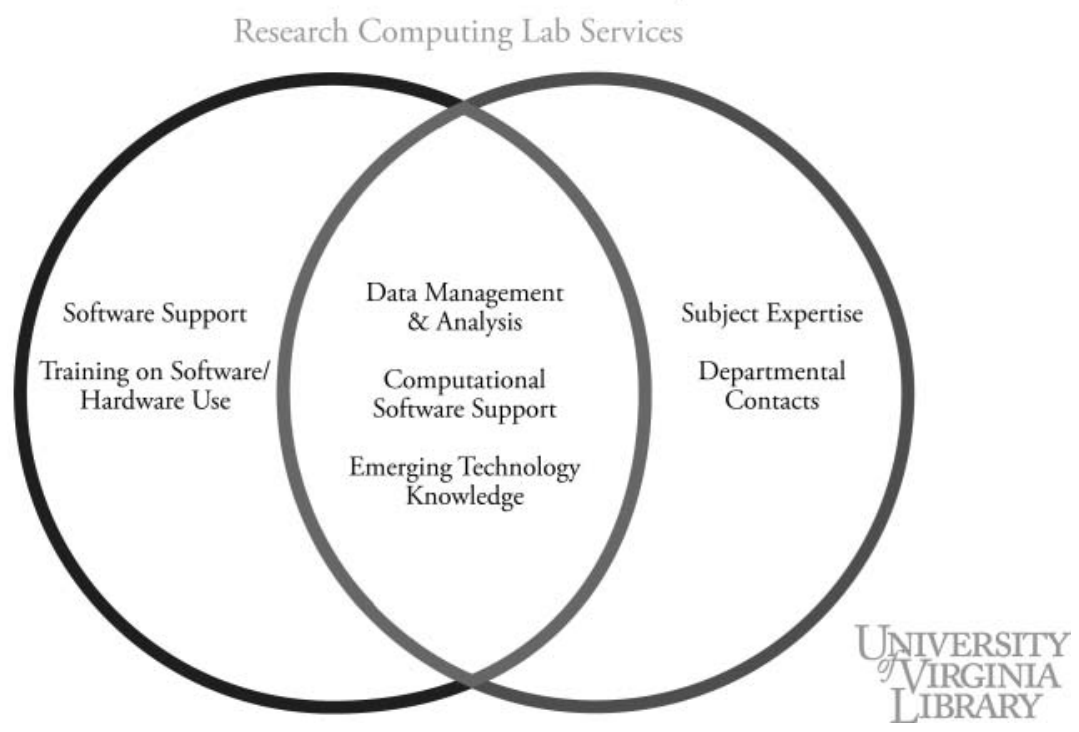

FIGURE 2 Representation of How Information Technology and Library Services Have Blended. 


\section{CONCLUSION}

The RCL's mission has developed incrementally and has been influenced by a variety of environmental factors. Guiding this process, however, is our philosophy that academic research libraries should provide information services support throughout the entire research lifecycle, not just in the information gathering phase. We have established strategic partnerships and developed important technical capabilities in order to provide these services. As we deal with the current period of fiscal constraints, most units in higher education will be working to define and sustain their core mission, while planning for future growth. The RCL is no exception. In the past several months, we have increased data curation, image integrity, and scientific publishing consulting, while continuing to maintain ongoing relationships that have been built over time; all on a flat or restricted budget. While the axiom "the only constant is change" may seem daunting, it is precisely this stance combined with a clear mission that will allow us to support a user base who, by their very definition, are on the cutting edge.

\section{NOTES}

1. See Reference Services Review, Volume 35, Number 3, 2007.

2. EDUCAUSE Core Data Service Fiscal Year 2007 Summary Report summarizes much of the data collected through the 2007 EDUCAUSE core data survey about campus IT environments at 994 colleges and universities in the U.S. and abroad. The 2005 Summary Report included summaries for 933 colleges and universities.

3. This is Outcome 4 from ARL E-Science Task Force Recommendations.

4. This is Outcome 3 from ARL E-Science Task Force Recommendations.

5. Association of Research Libraries-Coalition for Networked Information

\section{REFERENCES}

Association of College \& Research Libraries: Science \& Technology Section. (2009). Big science, little science, e-science: The science librarian's role in the conversation. Retrieved September 17, 2009, from http://www.ala.org/ala/mgrps/ divs/acrl/about/sections/sts/conferences/program09.cfm

Association of Research Libraries. (2008). Reinventing science librarianship: Models for the future. Proceedings from the ARL/CNI Fall Forum, October 16-17, 2008, Arlington, VA. Retrieved September 17, 2009, from http://www.arl.org/ resources/pubs/fallforumproceedings/forum08proceedings.shtml.

Association of Research Libraries. (2006). To stand the test of time: Long-term stewardship of digital data sets in science and engineering. A Report to the National Science Foundation from the ARL Workshop on New Collaborative Relationships: The Role of Academic Libraries in the Digital Data Universe, September 26-27, 2006, Arlington, VA. Retrieved September 17, 2009, from http://www .arl.org/bmdoc/digdatarpt.pdf 
Brandt, D. S. (2007). Librarians as partners in e-research: Purdue university libraries promote collaboration. College \& Research Libraries News, 68(6), 365-367, 396.

Committee on Institutional Cooperation. (2008). CIC library conference: Program. Retrieved September 17, 2009, from http://www-s.cic.net/programs/ CenterForLibraryInitiatives/Archive/ConferencePresentation/Conference2008/ program.shtml

Foster, A. L. (2008). Strains and joys color mergers between libraries and tech units. Chronicle of Higher Education, 54(19), A1-A13.

Garritano, J. R., \& Carlson, J. R. (2009). A subject librarian's guide to collaborating on e-science projects. Issues in Science \& Technology Librarianship, 57. Retrieved September 17, 2009, from http://www.istl.org/09sspring/refereed2.html

Gold, A. (2007). Cyberinfrastructure, data, and libraries, Part 2: Libraries and the data challenge: Roles and actions for libraries. D-Lib Magazine, 13(9/10). Retrieved September 17, 2009, from http://www.dlib.org/dlib/september07/gold/09goldpt2.html

Hawkins, B. L., \& Rudy, J. A. (2006). EDUCAUSE: Core data service: Fiscal year 2005 summary report. Boulder, CO: EDUCAUSE.

Hawkins, B. L., \& Rudy, J. A. (2008). EDUCAUSE: Core data service: Fiscal year 2007 summary report. Boulder, CO: EDUCAUSE.

Hernon, P., \& Powell, R. R. (Eds.). (2008). Convergence and collaboration of campus information services. Westport, CT: Libraries Unlimited.

Joint Task Force on Library Support for E-Science. (2007). Agenda for developing e-science in research libraries. Association of Research Libarires. Retrieved September 17, 2009, from http://www.arl.org/bm doc/ARL_EScience_final.pdf

Luce, R. E. (2008). A new value equation challenge: The emergence of eResearch and roles for research libraries. No Brief Candle: Reconceiving Research Libraries for the 21st Century, CLIR Report-pub142. Retrieved September 24, 2009, from http://www.clir.org/pubs/reports/pub142/luce.html

McKinzie, S. (2007). Library and IT mergers: How successful are they? Reference Services Review, 35(3), 340-343.

National Science Board. (2006). Science and engineering indicators 2006, Volume 1. NSB-06-01. Retrieved September 24, 2009, from http://www.nsf.gov/ statistics/seind06/

National Science Board. (2005). Long-lived digital data collections enabling research and education in the 21st century. NSB-05-40. Retrieved September 24, 2009, from http://www.nsf.gov/pubs/2005/nsb0540/

Palmer, C., Heidorn, P. B., Wright, D., \& Cragin, M. H. (2007). Graduate curriculum for biological information specialists: A key to integration of scale in biology. The International Journal of Digital Curation, 2(2), 31.

University of Virginia. (2007). Commission on the future of the University: Subcommittee on academic infrastructure. Retrieved October 1, 2009, from http:// www.virginia.edu/planningdocuments/commission/2MRC/Seconddrafts/all\%20 new\%20posted/5aReport.pdf 